\title{
Support System Developed for a Beginner's Design of Blended Learning Courses and Its Use Evaluation
}

\author{
${ }^{1}$ Isao Miyaji, ${ }^{1}$ Hayato Shimizu, ${ }^{2}$ Kouji Yoshida, ${ }^{3}$ Yoshinori Naruse \\ ${ }^{1}$ Okayama University of Science, ${ }^{2}$ Shounan Institute of Technology, \\ ${ }^{3}$ Toyama National College of Technology
}

\begin{abstract}
In recent years, as e-learning has become increasingly common, blended learning has become widespread. Using this teaching method, lectures and e-learning are combined in higher education institutions such as universities. E-learning will tend to be used more in the future. Therefore, blended learning is also highly likely to be widely used and to become more popular. To popularize it further, we developed a support system to enable even a beginner to design blended learning courses. The system includes a function to design blended learning, a function to make distributed document and a function for browsing samples. The first function includes both a lesson-plan-making function and a lesson-development-making function. Using the former, a user can produce weekly plans. Using the latter, a user can produce individual lesson plans. This paper reports the support system for the design of blended learning courses. We had users reply a questionnaire and performed the evaluation.
\end{abstract}

\section{Introduction}

In recent years, e-learning has been introduced into more than half of higher education institutions across Japan [1]. Among them, blended learning combining lectures and multimedia including elearning is expected to continue to spread in the future [2], [3]. At the same time, researchers have been examining how to conduct blended learning [4], [5], [6], [7]. One of the authors also is studying it [8], [9], [10].

Instructional design plays important roles to realize the charming, efficient and effective class [11], [12]. Before a class, we need to consider which media should be used, how they should be utilized, and when and where they should be handled. Blended learning is designed based on a teacher's experience. A teacher who conducts blended learning introducing e-learning for the first time often has no idea about what is needed or how materials and apparatus can be used. The system which can design from the class summary plan to the class details plan has been developed [13]. In this system, the authors consider the media as thing to present and spread teaching materials. This lacks the idea of the blended class to enhance a learning effect by combining appropriately the media with various characteristics.
When making a lesson plan, the support system for making educational guidance plan which decides one learning activity by inputting a necessary matter has been developed [14]. A lesson plan is made by making repeatedly the learning activity. This system was based on only a face-to-face class and was limited with three kinds of a blackboard demonstration, distribution document, and oral explanation as the media to use. Uchida [15] offers a media checklist to quantify the necessity of media. Users must list the kind of media that they need and then set out a relation between their lessons and those needs. In doing so, they need some knowledge about media. However, beginners at conducting blended learning must design their lessons without sufficient knowledge and therefore invariably encounter difficulties.

For that reason, we develop a support system with which beginners at blended learning can use elearning to produce their own lesson plans. After a user answers through replying some questions, lesson type is pointed to. Some lesson forms which consist of the lesson type are shown. After a user chooses one among them, media associated with designing blended learning are illustrated. A user of our system can choose some media to conduct blended learning without sufficient knowledge related to media. Furthermore, the user can make weekly plans, detailed lesson development for a class and distributed documents on the system.

In this paper, developed system is explained in sections 2 and 3 . Kinds and contents of databases used in the system are explained in sections 4 . The result showed that the system was highly evaluated by the user in section 5 .

\section{Outline of the developed system}

The developed system consists of five functions using six detabase. It has functions of both design of blended learning and production of distributed documents as shown in Figure 1. Using the former function, teaching plans of two types can be made: 15 weekly plans, and detailed lesson development for a class. Using the latter function, documents of three kinds can be produced: a consciousness survey, an evaluation sheet, and a term-awareness-rate survey. This system can show many reference samples that are browsable by users so that they can also produce the files necessary for their teaching 
plans using them as a reference. We will explain each function in the third chapter and give a detailed description of the database for producing teaching plans in the fourth chapter and thereafter.

The system that we developed this time was produced based on the idea of a supporting system to design the blended learning that we reported earlier. The developed system is designed for a beginner who tries to design a blended learning plan for the first time.

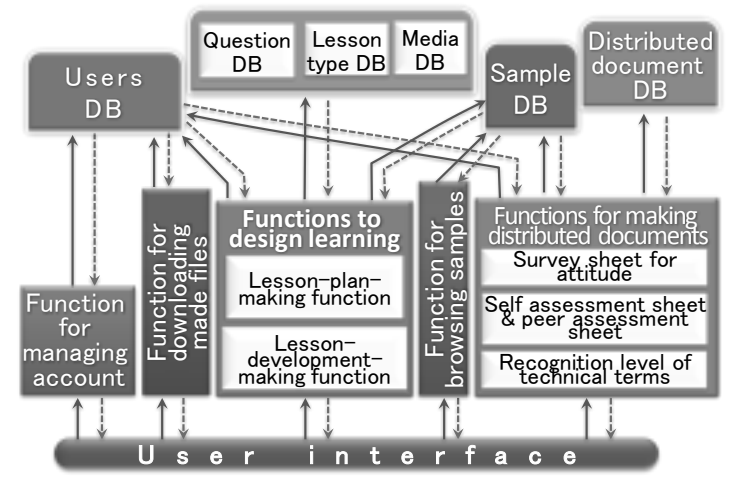

Figure 1. Construction of the developed system

\section{Functions to design blended learning}

The functions to design blended learning include the lesson-plan-making function and the classdevelopment-making function. Using the first function, the user can plan one class every week to make 15 classes in total; using the second function, the user can produce one detailed class development plan for a class. Flow of designing lesson is shown in Figure 2.

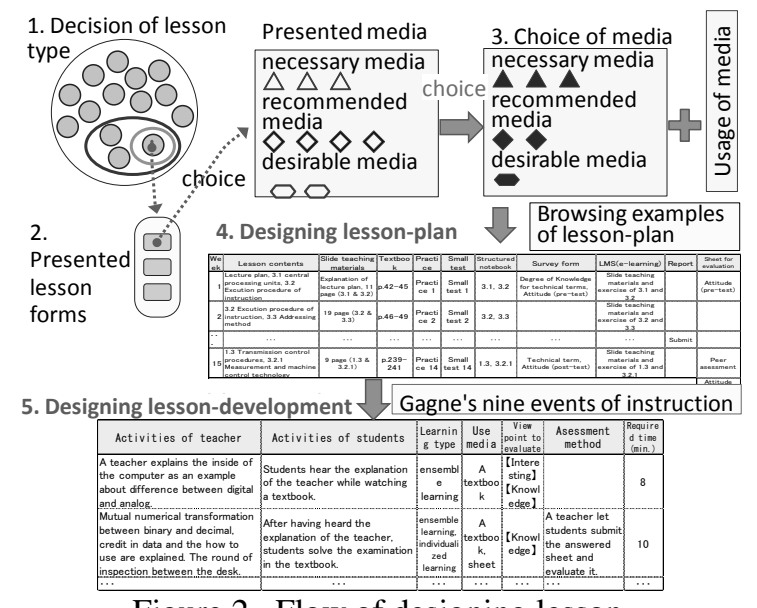

Figure 2. Flow of designing lesson

\subsection{Lesson-plan-making function}

Using the lesson-plan-making function, the user can make a lesson-plan through four stages as shown in Figure 2.
At the first stage, question 'a' which is shown in the second row of Table 1 appears on the screen to decide a lesson type among 14 lesson types shown in left of Table 2. When the user answers 2-5 questions among 13 questions in Table 1, the lesson type, into which blended learning is roughly classified, is determined among 14 lesson types as shown in Table 2.

At the second stage, some lesson forms which belong to the decided lesson type appear on the screen as shown in right of Table 2 . Figure 3 is an example presenting lesson forms belonging to decided lesson type. The user can choose the lesson form that is the closest to what the user is thinking among the lesson forms associated with the determined lesson types. The displayed lesson forms are gained by classifying each lesson type from the viewpoints of used media and others.

At the third stage, the user can determine some media to be used in the class. The media are shown as classified into three categories in descending order of frequency of use in the lesson form: necessary media, recommended media, and desirable media. Figure 4 is an example indicating the candidate of media which may be used in decided lesson form. From them, the user can choose the media for use in the class.

At the fourth stage, the columns of lesson contents and each media for 15 weeks is presented on the screen. The user can determine what to teach and how to use the media introduced for each class. The usage of media which are most often used in the class is shown as a sample. Adding to and altering that sample, the user can determine the usage on the web. The resultant teaching plan can be saved and downloaded as a CSV file. The part of example of finished files is displayed in Table 3.

Table 1. Flow for deciding a lesson type

\begin{tabular}{|l|l|c|c|}
\hline \multirow{2}{*}{$\begin{array}{l}\text { Qi } \\
\mathrm{gn}\end{array}$} & \multicolumn{1}{|c|}{ Questions } & \multicolumn{2}{|c|}{ Destination } \\
\cline { 2 - 4 } & Yes & No \\
\hline $\mathrm{a}$ & Are teachers and learners in distance away? & $\mathrm{b}$ & $\mathrm{g}$ \\
\hline $\mathrm{b}$ & Is lecture in remote areas synchronous? & $\mathrm{c}$ & $\mathrm{I}$ \\
\hline $\mathrm{c}$ & Are other media used in distance lecture? & $\mathrm{d}$ & $\mathrm{e}$ \\
\hline $\mathrm{d}$ & Are any media used to exercise in class? & 2 & 3 \\
\hline $\mathrm{e}$ & Is exchange done among learners? & 4 & $\mathrm{f}$ \\
\hline $\mathrm{f}$ & Is e-learning used outside the remote class? & 5 & 6 \\
\hline $\mathrm{g}$ & Is e-learning used? & $\mathrm{h}$ & $\mathrm{j}$ \\
\hline $\mathrm{h}$ & Is e-learning used in class? & $\mathrm{i}$ & $\mathrm{k}$ \\
\hline $\mathrm{i}$ & Is e-learning used in order to cooperate among the learners? & 7 & 8 \\
\hline $\mathrm{j}$ & Is the ICT used? & 13 & 14 \\
\hline $\mathrm{k}$ & Is cooperative learning conducted among the learners? & $\mathrm{I}$ & $\mathrm{m}$ \\
\hline $\mathrm{I}$ & Are the media used to cooperate? & 9 & 10 \\
\hline $\mathrm{m}$ & Is the use of e-learning evaluated? & 11 & 12 \\
\hline
\end{tabular}


Table 2. Kinds of lesson types and forms

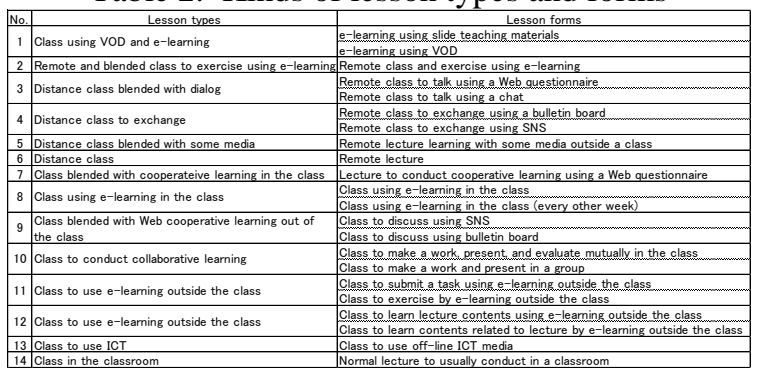

Lesson type "Lesson using VOD and e-learning"

Lesson form using slide material as main contents

(1) e-learning using slide material

Learning using slide material as main contents

(2) e-learning using VOD

Lesson using VOD animated
Figure 3. Example presenting lesson forms belonging of decided lesson type

\author{
Lesson form "E-learning using slide material" \\ (1) Necessary media \\ Lecture, LMS, Slide material \\ (2) Recommended media \\ Textbook, Frame of task, Distance lecture \\ (3) Desirable media \\ Discussion, Bulletin board, VOD, Exercise problem
}

Figure 4. Example indicating the candidate of media which may be used in decided lesson form

Table 3. Design example of lesson-plan

\begin{tabular}{|c|c|c|c|c|c|c|c|c|c|c|}
\hline $\begin{array}{l}\text { We } \\
\text { ek }\end{array}$ & Lesson contents & $\begin{array}{c}\text { Slide teaching } \\
\text { materials }\end{array}$ & $\begin{array}{l}\text { Text } \\
\text { book }\end{array}$ & $\begin{array}{c}\text { Practi } \\
\text { ce }\end{array}$ & $\begin{array}{c}\text { Mini } \\
\text { examina } \\
\text { tion }\end{array}$ & $\begin{array}{c}\text { Structured } \\
\text { notebook }\end{array}$ & Survey form & $\begin{array}{l}\text { LMS (e- } \\
\text { learning) }\end{array}$ & $\begin{array}{l}\text { Rep } \\
\text { ort }\end{array}$ & $\begin{array}{l}\text { Sheet for } \\
\text { evaluation }\end{array}$ \\
\hline 1 & $\begin{array}{l}\text { Lecture plan, } 3.1 \\
\text { central processing } \\
\text { units, } 3.2 \text { Excution } \\
\text { procedure of } \\
\text { instruction }\end{array}$ & $\begin{array}{l}\text { Explanation of } \\
\text { lecture plan, } \\
11 \text { page }(3.1 \\
\& 3.2)\end{array}$ & $\begin{array}{l}\text { p.42- } \\
45\end{array}$ & $\begin{array}{l}\text { Practi } \\
\text { ce } 1\end{array}$ & $\begin{array}{l}\text { Small } \\
\text { test } 1\end{array}$ & $3.1,3.2$ & $\begin{array}{c}\text { Degree of } \\
\text { Knowledge for } \\
\text { technical terms, } \\
\text { Attitude (pre- } \\
\text { test) }\end{array}$ & $\begin{array}{l}\text { Slide teaching } \\
\text { materials and } \\
\text { exercise of } 3.1 \\
\text { and } 3.2\end{array}$ & & $\begin{array}{c}\text { Attitude } \\
\text { (pre-test) }\end{array}$ \\
\hline 2 & $\begin{array}{l}\text { 3.2 Excution procedure } \\
\text { of instruction, } 3.3 \\
\text { Addressing method }\end{array}$ & $\begin{array}{c}19 \text { page (3.2 } \\
\& 3.3)\end{array}$ & $\begin{array}{l}\text { p.46- } \\
49\end{array}$ & $\begin{array}{l}\text { Practi } \\
\text { ce } 2\end{array}$ & $\begin{array}{l}\text { Small } \\
\text { test } 2\end{array}$ & $3.2,3.3$ & & $\begin{array}{l}\text { Slide teaching } \\
\text { materials and } \\
\text { exercise of } 3.2 \\
\text { and } 3.3\end{array}$ & & \\
\hline$\cdots$ & $\cdots$ & $\cdots$ & $\cdots$ & $\cdots$ & $\cdots$ & $\cdots$ & $\cdots$ & $\cdots$ & $\begin{array}{c}\text { Sub } \\
\text { mit }\end{array}$ & \\
\hline 15 & $\begin{array}{l}\text { 1.3 Transmission } \\
\text { control procedures, } \\
\text { 3.2.1 Measurement and } \\
\text { machine control } \\
\text { technology }\end{array}$ & $\begin{array}{c}9 \text { page }(1.3 \& \\
3.2 .1)\end{array}$ & $\begin{array}{l}\text { p.239 } \\
-241\end{array}$ & $\begin{array}{l}\text { Practi } \\
\text { ce } 14\end{array}$ & $\begin{array}{c}\text { Small } \\
\text { test } 14\end{array}$ & $1.3,3.2 .1$ & $\begin{array}{c}\text { Technical term, } \\
\text { Attitude (post- } \\
\text { test) }\end{array}$ & $\begin{array}{l}\text { Slide teaching } \\
\text { materials and } \\
\text { exercise of } 1.3 \\
\text { and } 3.2 .1\end{array}$ & & $\begin{array}{c}\text { Peer } \\
\text { asessmen } \\
t\end{array}$ \\
\hline & & & & & & & & & & $\begin{array}{l}\text { Attitude } \\
\text { (post- } \\
\text { test) }\end{array}$ \\
\hline
\end{tabular}

\subsection{Lesson-development-making function}

In the lesson-development-making function, the user makes the lesson development as the fifth stage in Figure 2. First, the CSV file names of lesson plans that have been made for a teaching plan in 3.1 are displayed. The user chooses a file which he/she hopes to make the lesson-development. Next, a window presents media that the user has determined to use in the development of the lesson and its usage. The user is required to input an activity about each one of Gagne's nine events of instruction. Then a table which includes activities of teacher, activities of students, learning type, use media, view point to evaluate, assessment method, and required time is displayed as shown in Table 4. The user inputs the column in reference to the examples. If the user clicks "save and confirmation," then the user views a table in the window as shown in Table 4 for confirmation. If it is OK, then the user clicks "save." The lesson development that has been made can be saved and downloaded as a CSV file. 
Table 4. Design example of lesson-development

\begin{tabular}{|c|c|c|c|c|c|c|}
\hline Activities of teacher & Activities of students & $\begin{array}{l}\text { Learnin } \\
\text { g type }\end{array}$ & $\begin{array}{l}\text { Use } \\
\text { media }\end{array}$ & $\begin{array}{l}\text { View } \\
\text { point to } \\
\text { evaluate }\end{array}$ & $\begin{array}{l}\text { Assessment } \\
\text { method }\end{array}$ & $\begin{array}{l}\text { Require } \\
\text { d time } \\
\text { (min.) }\end{array}$ \\
\hline $\begin{array}{l}\text { A teacher explains the inside of } \\
\text { the computer as an example } \\
\text { about difference between digital } \\
\text { and analog. }\end{array}$ & $\begin{array}{l}\text { Students hear the explanation } \\
\text { of the teacher while watching } \\
\text { a textbook. }\end{array}$ & $\begin{array}{c}\text { Ensembl } \\
\mathrm{e} \\
\text { learning }\end{array}$ & $\begin{array}{c}\text { Textbo } \\
\text { ok }\end{array}$ & $\begin{array}{l}\text { Interest } \\
\text { ing, } \\
\text { Knowle } \\
\text { dge }\end{array}$ & & 8 \\
\hline$\cdots$ & $\cdots$ & $\cdots$ & $\cdots$ & $\cdots$ & $\cdots$ & $\cdots$ \\
\hline $\begin{array}{l}\text { A teacher goes round and } \\
\text { instructs. }\end{array}$ & Students make an animation. & $\begin{array}{l}\text { Individua } \\
\text { lized } \\
\text { learning }\end{array}$ & $\begin{array}{l}\text { PC, } \\
\text { Flash }\end{array}$ & $\begin{array}{c}\text { Though } \\
t \\
\text { Techni } \\
\text { que }\end{array}$ & $\begin{array}{l}\text { Production is } \\
\text { evaluated. }\end{array}$ & 20 \\
\hline & & & & & Sum & 100 \\
\hline
\end{tabular}

\subsection{Distributed-documents-making function}

In the distributed-documents-making function, three kinds of survey sheet are made: survey sheet for attitude, survey sheet for evaluation assessment, and survey sheet for technical terms.

\subsubsection{Function for making survey sheet for attitude}

Attitude survey sheet is paper to investigate a change of the consciousness by a learner studying a subject. Attitude survey sheet is to investigate a change of the consciousness when a learner studies a subject. A user is required to input a subject name and investigation items to make this attitude survey sheet. 30 items and one item of the free description are displayed as a sample of the investigation items. The user corrects some of the items and makes modifications. The numbers of maximum items which a user can input a rating value and the freedom description are 35 items and two items respectively. A user save it after inputting them and can download attitude survey sheet as a CSV file.

In addition, a user can make attitude survey sheet with helpful activities for improving consciousness after the class end if a user continue to input the activity.

\subsubsection{Function for making survey sheet for evaluation}

An evaluation sheet is used when a learner evaluates a work and a report personally and mutually. A user input a work or a report name and the evaluation items to make this evaluation sheet.

Because item varies according to the kind of the work or the report, an example of the item is not displayed. While a user can download and browse some samples, a user may input evaluation items in reference to the sample. The number of evaluation items can be input up to 15 items. In addition, a user can make one item of a free description. The items of peer evaluation may be the same as those of selfevaluation. Because expression and entry content are different between self and peer evaluation sheet about the free description, a user input a different question sentence and then save it as a different sheet. The user can download the evaluation sheet as a CSV file.

\subsubsection{Function for making survey sheet about recognition level of technical terms}

The survey sheet about recognition level of terms is used to investigate how a learner knows the terms related to a subject. A user input a subject name and terms to investigate to make this survey sheet about recognition level of terms. The frame to input the terms is prepared for 50. A user save it after inputting them and can download the evaluation sheet as a CSV file.

\subsection{Function for browsing samples}

In a function for browsing samples, a user can browse the documents which a teacher distributes in the class or download the file to use as a sample. A screen to download sample files is displayed when a user clicks "Browsing of the sample" in a top page. A user can download files of lesson-plans, lessondevelopment and distributed-documents which a user has made. A user also can browse documents necessary to make a lesson-plan and development such as a structured notebook, sheet of mini examination, teaching material made with slides, and so on.

\section{Kinds and contents of databases}

Databases used in this system are six as shown in Figure 1: users, question, lesson type, media, document distributed, and sample. 


\subsection{Users database}

A user's database is storing the use log and a file that the user made. When a user registered, the directory of the user is made. The following six kinds of directories and files are stored: Directories to save the lesson-plan, the lesson-development, the attitude survey sheet, the evaluation sheet and the survey sheet for recognition level of technical terms that a user made, and the file which save a use history.

\subsection{Question database}

The question database, prepared in XML format, is used for producing teaching plans. Six tags are used in the question database: a question tag, a query tag, an explanation tag, a yes tag, a no tag, and a result tag. A partial structure of the question database is portrayed in the following. The question is the root tag, under which a yes tag, no tag, explanation tag, and query tag are structured. Regarding the yes tag and no tag, structures of two kinds exist. As with the root tag, one is structured by a yes tag, no tag, explanation tag, and query tag. The other is structured by a result tag alone. In the query tag, the question sentence to show is registered. In the explanation tag, the question sentence to show is also registered. In addition, in the ends of the yes tag and no tag, what is always structured using a result tag is registered.

\subsection{Lesson type database}

The lesson type database, prepared in XML format, is used in the lesson-plan-making function. In the lesson type database, the following are registered: the lesson type name, the lesson type explanation, the lesson form name, the lesson form explanation, the necessary media, the recommended media, the desirable media, and the usage of media. In the lesson form, the necessary media, the recommended media, and the desirable media are registered in descending order of frequency of introduction in a class. As the usage of media, that of the media which is most often used among registered media is registered. The usage is registered in figures. Each figure stands for the number assigned to the media database. The number determines the usage of media in the lesson form.

\subsection{Media database}

The media database, prepared in XML format, is used in the lesson-plan-making function. In the media database, the following are registered: the media name, the media explanation, the usage, and the example of the media collaborated with other media, and the usage of media through a whole class. The number of usage depends on the medium. Even if the media are the same, how to use them or the frequency of their use might vary according to the usage. Consequently, even if the way of introduction is the same, when the frequency of use differs, it is registered as a different usage.

\subsection{Document distributed database}

The document distributed database, saved in CSV format, is used in the document-distributed making function. In it are registered the following: the frameworks of survey sheet for attitude, the evaluation sheet, and the survey sheet for recognition level of technical terms, in addition to the items of the consciousness survey and the items of activities useful for changing consciousness.

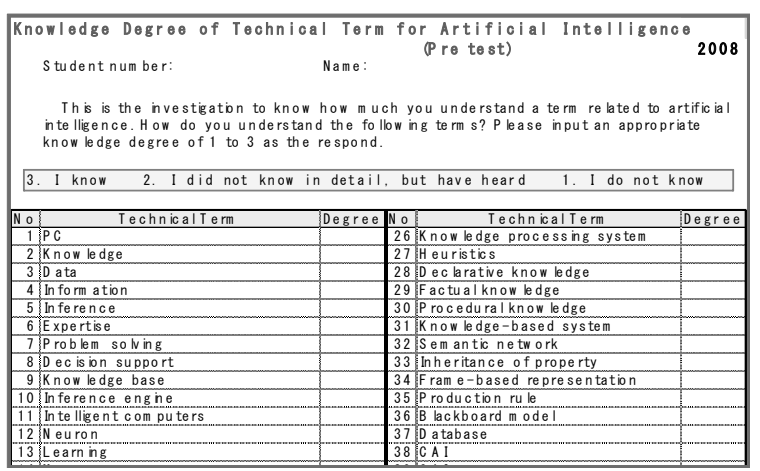

Figure 5. Example of survey sheet for recognition level of technical terms

\subsection{Sample database}

In the sample database, many files are registered so that the user can browse and refer to them to make a teaching plan or documents distributed. In the sample database, the following are registered lesson plans, lesson development, survey sheet for attitude, the evaluation sheet, and the survey sheet for recognition level of technical terms that can be made using this system. The following are also registered: structured notes, quizzes, and slide-show teaching materials, which are necessary when conducting real classes.

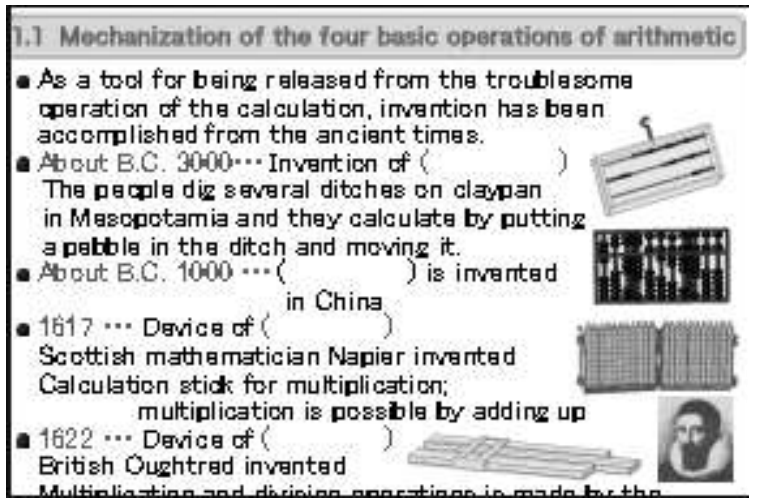

Figure 6. Example of distributed document 


\section{Analysis of the questionnaire}

Because we required users, teachers and students, to use and evaluate the system which we developed, the results are explained. The difference was calculated at a 5\% significant level. $\mathrm{m}, \mathrm{SD}$ and $\mathrm{p}$ mean the average, standard deviation and significant probability respectively.

\subsection{Results of questionnaire about teachers}

The teachers or instructors used the system for designing own class and making weekly plans, detailed lesson development for a class, and distributed documents. Then, they replied questionnaire which consists of 23 items as shown in Table 5. The rating values for items 1 to 19 are replied by the five rating scale. The five rating values are as follows: 1. Not adapted; 2. Not slightly adapted; 3. Neutral; 4. Slightly adapted; 5. Adapted. A part of the result is shown in Table 5. Seven respondents completed the questionnaires.

About items 1 to 19 , it was examined by the Wilcoxon signed-ranks test whether average rating values deflect to an affirmative side or a negative side in association with "3. Neutral". As a result, the average rating value for all items 1 to 19 deflected significantly to the affirmative side.

Items 1 to 3 relate to questions to choose a class type. Deflection to the affirmative side for the item 1 tended to be significant at a $10 \%$ level. Deflection to the affirmative side for the item 2 was significantly recognized. Deflection to for the item 3 was not recognized. This result shows that tenor and contents are adequate, but since the number of questions is a few, we must go through to increase the number.

Items 4 and 5 relate to questions to choose a lesson form. Deflection to the affirmative side for the item 4 tended to be significant at a $10 \%$ level. Deflection to the affirmative side for the item 5 was significantly recognized at a $5 \%$ level. This result shows that the number of lesson forms did not satisfy themselves even though they could choose an adequate form.

Items 6 to 8 relate to the media registered with the lesson form. Deflection to the affirmative side for all these items was significantly recognized. Because all evaluations of these items were more than 3, this shows that these items were highly rated. However, because frequency of "4. Slightly adapted" is most in these items, it is indicated that there is yet room for improving to fit necessary media, recommended media, and desirable media.

Item 16 relates to the distributed documents. Deflection to the affirmative side for the item was significantly recognized. Since the number of samples in the distributed documents was highly rated, the users satisfied the number. However, they did not satisfy kinds of distributed documents because deflection for item 14 relates the kinds was not recognized.

It was recognized that item 19 deflected significantly to the affirmative side. This shows that the users want to use the system in the future. It means that the users have felt effective and efficient for using the system.

Item 20 is a question about the number of times that a user revised a lesson plan after having downloaded it. The average number of times revised was 1.5 times. The maximum was three times, and the minimum was 0 times. The persons who revised once and twice are each two. One person revised it three times. There was one person who did not revise at all. The person who revised made a lesson plan on this system roughly and described that he/she modified after having downloaded it. It is regarded as the reason that a user revised more than once because it allowed a user to download a lesson plan with a CSV file.

Item 21 is a question about the number of times that a user revised after having made a distribution document. The mean of this item was 1.2 times. The maximum was three times, and the minimum was 0 times. The persons who did not revise was three, the persons who revised twice was two, and the person who revised three times was alone. Half of users did not revise a distributed document. Because a user often use attitude survey sheet and the recognition investigation sheet only by the first class and the last class among the distribution documents which a user can make by this system and do not need it immediately, it is supposed that a user might not revise it.

Item 22 is really a question about the time that it took to make a lesson plan. The average of this item was 144 minutes. The minimum and the maximum were 30 and 420 minutes respectively. Persons with less than 60 minutes, with 61-100 minutes, and with 101 minutes or more were three, alone, and two respectively. Two persons with less than 90 minutes described that they roughly made a lesson plan using the system and modified it after downloading. In the case of different form from the usual form of lesson plan, it was found that it takes more than usual.

Item 23 is a question about the decrease of time to make a lesson plan. The average was 13.3 minutes. The minimum and the maximum were -30 and 30 minutes. The person who did not change was three and the person who decreased less than 30 minutes was three. On the contrary, the person who answered that making time increased was alone. 
Table 5. Results of questionnaire about teachers

\begin{tabular}{|c|c|c|c|c|c|}
\hline No: & Items for evaluation & $\mathrm{m}$ & SD & z & $\mathrm{p}$ \\
\hline 1 & Were the words of the question to choose a lesson type appropriate? & 3.9 & 0.7 & 2.2 & + \\
\hline 2 & Was the content of the question to choose a lesson type appropriate? & 4.3 & 0.5 & 2.5 & $*$ \\
\hline 3 & Was the number of questions enough when choosing a lesson type? & 3.6 & 0.8 & 1.6 & \\
\hline 4 & Were the number of lesson forms registered with a lesson type enough? & 4.0 & 0.8 & 2.2 & + \\
\hline 5 & Were you able to choose a lesson type and a lesson form that yourself thought of? & 4.4 & 0.8 & 2.3 & $*$ \\
\hline 6 & Was the necessary media registered with a lesson form appropriate? & 4.1 & 0.7 & 2.3 & $*$ \\
\hline 7 & Was the recommended media registered with a class form appropriate? & 3.9 & 0.4 & 2.5 & $*$ \\
\hline 8 & Was the desirable media registered with a class form appropriate? & 4.0 & 0.6 & 2.4 & $*$ \\
\hline 9 & Was the explanation for usage of media appropriate? & 3.7 & 1.0 & 1.7 & \\
\hline 10 & Was the content of the sample for usage of media appropriate? & 3.7 & 1.0 & 1.7 & \\
\hline 11 & Was the frame in the screen of lesson-development-making appropriate? & 4.0 & 0.8 & 2.2 & + \\
\hline 12 & Was the example of lesson-development appropriate? & 3.4 & 1.0 & 1.1 & \\
\hline 13 & Was the made lesson-plan the form that you expected for? & 3.4 & 0.5 & 1.7 & \\
\hline 14 & Were kinds of distributed documents which you could make enough? & 3.6 & 1.0 & 1.4 & \\
\hline 15 & Was the framework of distributed documents which you could make appropriate? & 3.6 & 0.5 & 2.0 & \\
\hline 16 & Was the number of samples for distributed documents enough? & 4.4 & 0.8 & 2.3 & $*$ \\
\hline 17 & Was the number of samples for lesson plan enough? & 4.1 & 0.9 & 2.2 & + \\
\hline 18 & Did you reduce time to make a lesson plan in comparison with usual times? & 2.9 & 1.1 & -0.2 & \\
\hline 19 & Do you want to use this system in future? & 4.1 & 0.7 & 2.3 & $*$ \\
\hline & Average & 3.8 & 0.3 & 2.0 & $*$ \\
\hline 20 & After having made a lesson plan, how many times did you correct it? & 1.5 & 1.1 & \multirow{4}{*}{\multicolumn{2}{|c|}{$\begin{array}{l}* p<.05 \\
+p<.1\end{array}$}} \\
\hline 21 & After having made distributed documents, how many times did you correct it? & 1.2 & 1.3 & & \\
\hline 22 & How much time did it take to make a lesson plan? & 120.5 & 157.9 & & \\
\hline 23 & How much time did you decrease to make a lesson plan? & 13.3 & 15.1 & & \\
\hline
\end{tabular}

\subsection{Results of questionnaire about students}

Using the system, students were required to make the report of task "Designing blended class about any contents of information studies in a high school" in "Introduction to e-learning" that is an elective subject in third-year student of University A. Therefore the lesson-plan-making function in the system was improved to adapt to the task. By the lesson-planmaking function, media are chosen as explained in section 2. Then, a screen to input how to use media and a use point is displayed. After that, a student can make a file adapted to the task.

The student who used it was required to reply questionnaire which consists of 23 items. The questionnaire is the same as one for teachers. The rating values for items 1 to 19 are replied by the five rating scale. The results are shown in Table 6 . Twenty-six respondents completed the questionnaires. About items 1 to 19 , it was examined by t-test whether average rating values deflect to an affirmative side or a negative side in association with "3. Neutral". As a result, the average rating value for all items 1 to 19 deflected significantly to the affirmative side.

Items 1 to 3 relate to questions to choose a lesson type. Deflection to the affirmative side for all these items was significantly recognized. This result shows that a method to decide a lesson type by choosing one choice among two, then to choose a lesson form from some ones belonging to the lesson type is highly rated.

Items 6 to 8 relate to the media registered with the lesson form. Deflection to the affirmative side for all these items was significantly recognized. Because all these items were more evaluations than 3 , this shows that these items were highly rated. However, because frequency of "4. Slightly adapted" is most in these items, it is indicated that there is yet room for improvement in these items.

Deflection to the affirmative side for all these items 9 and 10 about the usage of the media was significantly recognized. As the cause that the evaluation of these items was not so high, because usage and explanation of the media is abstract, it is thought that a user could not understand how to use. About explanation and the usage of the media and a sample of usage, it is thought that it is necessary to modify in a more plain description.

Item 11 was a question about the adequacy of the framework of lesson-development-making. It was admitted that it significantly deflected to the affirmative side. In this system, a user makes lessondevelopment after having gone through about Gagne's nine events of instruction. it is thought that many students might rate affirmatively because a student was able to make lesson development in a procedure as a student learned in a class.

Item 12 was a question about the adequacy of examples of the lesson development. It was recognized that it significantly deflected to the affirmative side. However, rating value was a little low. As cause for this, it is thought that lower rating was brought because there are only three files registered into the sample database.

Item 13 is a question about the forms of the lesson plan. It was recognized that it significantly deflected to the affirmative side. This item is not similarly 
high to the teacher's use evaluation. It is thought that there was big difference between media that matched usage that a user thought or media that did not match.

Item 14 is a question about the number of the kinds of distributed document which a user can make using this system. It was recognized that it significantly deflected to the affirmative side. A student described the comment that the system will be better to have the function for making miniexamination. In order to improve the system, we consider to increase the files which a user can make.

Item 15 is a question about the adequacy of the frame of distributed document which a user could make. It was recognized that it significantly deflected to the affirmative side. The rating value of this item was lower than the whole mean. However, half of students rated 3 and there was no student who rated less than 3. Because the distributed document is not obliged to hand in, and the student did not show much interest, it is thought that the rating value might be lower.

Item 16 was a question about the number of samples of distributed document. It was recognized that it significantly deflected to the affirmative side. Attitude survey sheet was introduced most in the documents which a user could make by the distributed-documents-making function. It is noted that 20 persons of 26 students introduced to their reports. However, the number of the files of distributed document registered with the sample database was 4, 10 and 10 about survey sheet for attitude, survey sheet for evaluation and survey sheet for recognition level of technical terms respectively. The number of survey sheet for attitude was least. It is thought that it is necessary to increase the number of files of survey sheet for attitude into the sample database.

Item 17 was a question about the number of samples of lesson plan. It was recognized that it significantly deflected to the affirmative side. Because there were nine samples of lesson plan in the sample database, it is thought that this evaluation was obtained. Furthermore, it is necessary to increase the number of samples and to make a referring sample clear through classifying them with a lesson type in order to raise the evaluation of this item.

It was recognized that the item 18 deflected significantly to the affirmative side at a $0.1 \%$ level. This shows that the time for making the lesson plan shortened using the system. It means that the making time generally shorten using the system because there was no student who replied that making time gets longer. It was recognized that the time varies among different individuals because the standard deviation of item is big.

Item 19 was a question about the satisfaction using a system. It was recognized that it significantly deflected to the affirmative side. Standard deviation of this item is biggest in item 1-19. It was found that a difference between the evaluations of students is big. The student who estimated it as 1-3 in this item rated item 18 as 1-3. It is thought that users who were not able to shorten the time making lesson plans lowered the evaluation of satisfaction.

Item 20 is an question about the number of times revised after having downloaded a lesson plan. The average was 2.23 times. The minimum was 0 times, and the maximum was ten times. The number of students who revised 0 time, once, twice, tree times and more than four times was 5, 10, 5, 2 and 4 persons respectively.

Item 21 is a question about the number of times that a user revised a distributed document after having made it. The average was 1.17 times. The minimum and the maximum were 0 times and five times respectively. The persons who revised 0 time, once, twice, third times and four times was 9, 8, 5, 3 and 1 respectively. The number of times that a user revised distributed document was less than those of the lesson plan. Because the distributed document is not obliged to present, it is supposed that a student only made it.

Item 22 is really a question about the time that it took for making lesson plan. The average time about this item was 76.5 minutes. The minimum and the maximum time were 10 and 300 minutes respectively.

Item 23 is a question about the decrease of the time to make a lesson plan. The average of decreased time was 32.0 minutes. The minimum and the maximum time were 0 and 150 minutes respectively.

We calculated Spearman coefficient of correlation between the rating values in item 19 about the satisfaction and the decreased time in item 23. The coefficient of correlation was 0.28 and was not significantly. This was the same result as one for teachers. This result does not mean that to decrease the time for making lesson plan raises satisfaction using this system. 
Table 6. Results of questionnaire about students.

\begin{tabular}{|c|c|c|c|c|c|}
\hline No: & Items for evaluation & $\mathrm{m}$ & SD & $\mathrm{t}$ & $\mathrm{p}$ \\
\hline & Were the words of the question to choose a lesson type appropriate? & 3.9 & 0.8 & 5.6 & $* * *$ \\
\hline 2 & Was the content of the question to choose a lesson type appropriate? & 3.9 & 1.0 & 4.5 & $* * *$ \\
\hline 3 & Was the number of questions enough when choosing a lesson type? & 4.0 & 0.9 & 5.6 & $* * *$ \\
\hline 4 & Were the number of lesson forms registered with a lesson type enough? & 3.7 & 0.9 & 3.9 & $* * *$ \\
\hline 5 & Were you able to choose a lesson type and a lesson form that yourself thought of? & 3.7 & 0.9 & 3.6 & $* *$ \\
\hline 6 & Was the necessary media registered with a lesson form appropriate? & 3.5 & 1.0 & 2.5 & $*$ \\
\hline 71 & Was the recommended media registered with a class form appropriate? & 3.5 & 0.9 & 2.8 & ** \\
\hline 8 & Was the desirable media registered with a class form appropriate? & 3.6 & 0.8 & 3.6 & ** \\
\hline & Was the explanation for usage of media appropriate? & 3.4 & 0.9 & 2.1 & $*$ \\
\hline 10 & Was the content of the sample for usage of media appropriate? & 3.4 & 0.8 & 2.7 & $*$ \\
\hline 11 & Was the frame in the screen of lesson-development-making appropriate? & 3.5 & 0.7 & 3.9 & $* * *$ \\
\hline 12 & Was the example of lesson-development appropriate? & 3.5 & 0.8 & 3.4 & $* *$ \\
\hline 13 & Was the made lesson-plan the form that you expected for? & 3.5 & 0.8 & 3.1 & ** \\
\hline 14 & Were kinds of distributed documents which you could make enough? & 3.5 & 0.7 & 3.6 & $* *$ \\
\hline 15 & Was the framework of distributed documents which you could make appropriate? & 3.4 & 0.6 & 3.1 & $* *$ \\
\hline 16 & Was the number of samples for distributed documents enough? & 3.3 & 0.6 & 2.3 & $*$ \\
\hline 17 & Was the number of samples for lesson plan enough? & 3.4 & 0.6 & 2.8 & ** \\
\hline & Did you reduce time to make a lesson plan in comparison with usual times? & 3.8 & 0.8 & 5.1 & $* * *$ \\
\hline & Do you want to use this system in future? & 3.7 & 1.1 & 3.1 & $* *$ \\
\hline & Average & 3.6 & 0.8 & 15.2 & $* * *$ \\
\hline 20 & After having made a lesson plan, how many times did you correct it? & 2.0 & 2.2 & \multirow{4}{*}{\multicolumn{2}{|c|}{$\begin{array}{c}* * * \mathrm{p}<.001 \\
* * \mathrm{p}<.01 \\
* \mathrm{p}<.05\end{array}$}} \\
\hline 21 & After having made distributed documents, how many times did you correct it? & 1.2 & 1.2 & & \\
\hline 22 & How much time did it take to make a lesson plan? & 76.5 & 65.4 & & \\
\hline 23 & How much time did you decrease to make a lesson plan? & 32.0 & 35.1 & & \\
\hline
\end{tabular}

\section{Conclusion}

Many media exist to support blended learning. For that reason, it is difficult for a beginner to choose which media to use. Therefore, we proposed and developed this lesson-design support system with which users can set out main media to use for a class merely by answering several questions without sufficient knowledge for media.

The results of the questionnaire showed that the users recognized that the system was highly appropriate. The students who attended "Introduction to e-learning" that was an elective subject in thirdyear in University A were required to use this system and to reply a questionnaire about use evaluation. As a result, all of items 1-19 was significant in the affirmation side. It was recognized that items 1-4, which related to a question to choose a lesson type, were significant. From this, students highly rated how to choose one of the lesson forms which belong to the class type, after having decided a lesson type by replying the question of two choices. Students recognized that the time for making the lesson plan shortens by using this system. However, because standard deviation about the making time is great, the making time which the system shorten depend heavily on persons.

In the future, we would like to improve this system so that users are easy to use and operate by referring the results of questionnaire.

\section{Acknowledgement}

The authors appreciate the support of the Grantin-Aid for Scientific Research, foundation study (C22500949) provided by the Ministry of Education, Culture, Sports, Science and Technology, Japan for this research.

\section{References}

[1] Japan E-learning Consortium (Ed.), "White book on Elearning 2008/2009," pp.58-83, Tokyo Denki University Publishing, Tokyo, Japan, 2008.

[2] Ministry of Education, Culture, Sports, Science and Technology, "Program for promoting leading education computerization," http://www.mext.go.jp/, 2009. (Access date: 22 September 2010)

[3] Ministry of Public Management, Home Affairs, Posts and Telecommunications, Study group for the collaboration educational promotion which utilizes ICT, http://www.soumu.go.jp/, 2010. (Access date: 10 April 2011)

[4] Adachi, K., "Analysis of the classification of the learners' activities in blended learning", Japan Journal of Educational Technology, Vol.3, No.1, (2007) pp.29-40.

[5] Bersin, J., The blended learning book: Best practices, proven methodologies, and lessons learned. Pfeiffer, San Francisco, USA, 2004.

[6] Fujishiro, N., Hiramatsu, S., and Miyaji, I., "Effects of communication practice utilizing the digital learning materials based on WBT for English listening in the 
blended learning approach," Japan Journal of Educational Technology, Vol.31, Suppl., 2007, pp.8588.

[7] Miyaji, I. (Ed.), "Toward Blended Learning from Elearning," Kyoritu-Shuppan, Tokyo, Japan, 2009.

[8] Miyaji, I. and Yoshida, K., "The practice and learning effect of education by blending of lecture and elearning," Transactions of Japanese Society for Information and Systems in Education, Vol.22, No.4, 2005, pp.230-239.

[9] Miyaji, I., Yoshida, K., and Naruse, Y., "The effects of blending e-learning and lectures utilizing a structured notebook," Transactions of Japanese Society for Information and Systems in Education, Vol.24, No.3, 2007, pp.208-215.

[10] Miyaji, I. \& Li, Z., "Video conferencing between a university in Japan and a university in China and its effects on the promotion of students' research using their respective mother tongue, " The Journal of information and systems in education, Vol.7, No.1, pp.49-58, 2008.

[10] Miyaji, I., "Comparison between effects in two blended classes which e-learning is used inside and outside classroom," US-China Education Review, USA, Vol.8, No.4, pp.468-481, 2011.

[11] Gagne, R.M., Wager, W.W., Golas, K.C., and Keller, J.M., Principles of Instructional Design, Wadsworth: A division of Thomson Learning, Toronto, 2005.

[12] Lee, W.W. and Owens, D. L., Multimedia-based instructional design: computer-based training, webbased training, distance broadcast training, performance-based solutions, Jossey-Bass/Pfeiffer, New York, USA, 2001.

[13] Nakadake, O., "Development of System concerned with teaching plan," Journal of Japanese Society for Educational Information, Vol.5, No.3, 1989, pp.74-84.

[14] Souma, T., Kouno, S., Gotoh, T., et al., "Development and evaluation of a computer supported system to draw up teaching plan," IECE Technical Report, Vol.99, No.459, pp.43-50, 1999.

[15] Uchida, M., Practice on Instructional Design, Tokyo Denki University Publishing, Tokyo, Japan, 2005. 